\title{
The PERK Branch of the Unfolded Protein Response Promotes DLL4 Expression by Activating an Alternative Translation Mechanism
}

\author{
Manon Jaud ${ }^{1,+}$, Céline Philippe ${ }^{1,+}$, Loic Van Den Berghe ${ }^{1,2}$, Christèle Ségura $^{1,2}$, \\ Laurent Mazzolini ${ }^{1}$ (D), Stéphane Pyronnet ${ }^{1}$, Henrik Laurell ${ }^{3}$ and Christian Touriol ${ }^{1, *}$ (D) \\ 1 Inserm UMR1037, CRCT (Cancer Research Center of Toulouse), CNRS ERL5294, Université Toulouse III \\ Paul-Sabatier, F-31037 Toulouse, France; manon.jaud@inserm.fr (M.J.); c.philippe@qmul.ac.uk (C.P.); \\ Loic.Vandenberghe@inserm.fr (L.V.D.B.); christele.segura@inserm.fr (C.S.); \\ laurent.mazzolini@inserm.fr (L.M.); stephane.pyronnet@inserm.fr (S.P.) \\ 2 Vectorology Plateform, Technological pole CRCT, F-31037 Toulouse, France \\ 3 Inserm UMR1048, I2MC (Institut des Maladies Métaboliques et Cardiovasculaires), Toulouse, France; \\ henrik.laurell@inserm.fr \\ * Correspondence: christian.touriol@inserm.fr \\ + These two authors contributed equally to this work.
}

Received: 3 December 2018; Accepted: 22 January 2019; Published: 25 January 2019

\begin{abstract}
Delta-like 4 (DLL4) is a pivotal endothelium specific Notch ligand that has been shown to function as a regulating factor during physiological and pathological angiogenesis. DLL4 functions as a negative regulator of angiogenic branching and sprouting. Interestingly, Dll4 is with Vegf- $a$ one of the few examples of haplo-insufficiency, resulting in obvious vascular abnormalities and in embryonic lethality. These striking phenotypes are a proof of concept of the crucial role played by the bioavailability of VEGF and DLL4 during vessel patterning and that there must be a very fine-tuning of DLL4 expression level. However, to date the expression regulation of this factor was poorly studied. In this study, we showed that the DLL4 5'-UTR harbors an Internal Ribosomal Entry Site (IRES) that, in contrast to cap-dependent translation, was efficiently utilized in cells subjected to several stresses including hypoxia and endoplasmic reticulum stress (ER stress). We identified PERK, a kinase activated by ER stress, as the driver of DLL4 IRES-mediated translation, and hnRNP-A1 as an IRES-Trans-Acting Factor (ITAF) participating in the IRES-dependent translation of DLL4 during endoplasmic reticulum stress. The presence of a stress responsive internal ribosome entry site in the DLL4 msRNA suggests that the process of alternative translation initiation, by controlling the expression of this factor, could have a crucial role in the control of endothelial tip cell function.
\end{abstract}

Keywords: DLL4 (delta like ligand 4); angiogenesis; IRES (internal ribosome entry site); hypoxia; endoplasmic reticulum stress; UPR (unfolded protein response); PERK (PKR-Like endoplasmic reticulum kinase)

\section{Introduction}

Coordinately expressed and regulated genes control most physiological processes. This is the case for angiogenesis, the process of the expansion of existing blood vessel mainly by sprouting new branches from pre-existing blood vessels and leading to the outgrowth of new capillaries to form a new functional vascular network.

Angiogenesis is critical for many physiological processes such as embryonic development, wound healing, or vessel penetration into avascular regions and in pathological states including retinopathy, chronic inflammatory disorders (e.g., psoriasis or rheumatoid arthritis) and of course solid tumor 
development. Angiogenesis depends on the highly coordinated actions of a variety of pro-angiogenic regulators, the most prominent and best characterized being Vascular Endothelial Growth Factor A (VEGF-A) and Fibroblast Growth Factor 2 (FGF-2) which were among the first pro-angiogenic molecules to be identified [1].

Among the stimuli responsible for the up-regulation of pro-angiogenic factors, hypoxia has been of particular interest because of its role in cancer progression. It is clearly established that VEGF-A and FGF-2 are strongly expressed in hypoxic tissues, allowing the recruitment of new blood vessels from surrounding territories to ensure their needs of oxygen and nutrients. Hypoxia contributes to angiogenesis by transcriptionally activating several angiogenic factors as well as their receptors thus facilitating the recruitment of endothelial cells to the site of hypoxia, but VEGF-A and FGF-2 expression is also up-regulated under hypoxic conditions [2,3] and after ER stress [4] through Internal Ribosome Entry Site (IRES)-mediated translation [5]. After tissue reoxygenation, the expression of angiogenic factors decreases. This elegant negative feedback mechanism is a key event in the regulation of blood vessel growth.

However, the vascular response to angiogenic factors is also dependent on other regulatory mechanisms. Several studies demonstrate that one such regulator essential for tumor neovascularization is the NOTCH ligand DLL4, which is one of three delta-like ligands in the mammalian genome [6]. DLL4 is an important component of the NOTCH pathway, which is critical for embryonic vascular development and arterial specification. It is weakly expressed in adult tissues, but markedly induced in murine and human tumor vasculature [7-9]. Using different experimental models and a variety of genetic and pharmacologic approaches, several studies report that the DLL4/NOTCH pathway is a critical negative regulator of tumor angiogenesis, acting to restrain excessive VEGF-induced vascular sprouting and angiogenesis. The DLL4 pathway regulates sprouting and branching behaviors by influencing the formation of vascular 'tip cells'-specialized endothelial cells at the leading edge of vascular sprouts [10-16]. The tip cells which express high levels of VEGFR-2, VEGFR-3 and platelet-derived growth factor-B, are characterized by their cellular protrusions or filopodia that sense the local environment and migratory behavior to guide the growth of new blood vessels towards the source of angiogenic growth factors [17]. VEGFR2 signaling induces the expression of the Notch ligand DLL4 on the surface of the tip cell membrane allowing the suppression of tip-cell features in adjacent stalk cells via DLL4/NOTCH-mediated lateral inhibition [18]. Then the endothelial stalk cells follow the polarized migration of tip cells and proliferate in order to form new blood vessels.

During this process, endothelial cells are exposed to gradient of oxygen [19]. Indeed, since lumen formation of new vessel has not occurred, blood flow is not present, thus endothelial cells from these new blood vessels are under hypoxia, especially the tip cells due to their position furthest away from the circulating blood. It was demonstrated that Dll4 haploinsufficiency causes embryonic lethality and reduces tumor growth due to defects in the development of the vasculature $[7,20]$. These striking phenotypes resulting from heterozygous deletion of Dll4 indicate that vascular development may be very sensitive to subtle changes in Dll4 expression. Interestingly VEGF-A and DLL4 are the only proteins for which the heterozygosity results in a lethal embryonic phenotype and obvious vascular abnormalities, highlighting the essential and unique role of both proteins during angiogenesis $[7,21,22]$.

Furthermore, several data indicate that VEGF-A and DLL4 are coordinately expressed and that VEGF activates DLL4 expression via VEGFR2 signaling [15,18,23,24]. Moreover, in vitro, hypoxia can induce transcription activation of both Vegf- $a$ and Dll4 in endothelial cells [25]. Finally, endothelial expression of DLL4 was demonstrated to be significantly associated with VEGF-A in many cancers including glioma, colon, nasopharyngeal and lung cancers [26-29]. Taken together, these data indicate a potential co-regulation of these two genes.

It is well known that DLL4 expression is regulated by transcriptional and post-transcriptional (i.e., $3^{\prime}$-end processing) mechanisms, but the translational regulation of DLL4 messenger has not yet been studied. In this study, we sought to further investigate the role of stress responses in DLL4 expression regulation. We have identified an Internal Ribosome Entry Site (IRES) in the 5'-UTR of DLL4 
mRNA which is activated under hypoxic and ER stress conditions. Further, we have identified PKR-like ER-associated protein kinase (PERK), a kinase activated during ER stress which phosphorylates the eIF2 $\alpha$ subunit and impairs the generation of the ternary complex Met-tRNAi-eIF2-GTP, as the main regulator of DLL4 IRES-mediated translation and hnRNPA1 as an IRES Trans Acting Factor regulating DLL4 IRES-mediated translation during stress.

\section{Results}

\subsection{The Human DLL4 Transcript Contains a Functional IRES Which is Active in Different Cell Types}

Strong conservation of non-coding exonic sequences during vertebrates' evolution often means involvement in post-transcriptional regulation of gene expression [30]. Interestingly, DLL4 5'-UTR shows fairly high conservation, with more than 70\% mRNA sequence identities between 14 mammal species (Figure S1A). This indicates that this non-coding region may contain functional RNA structures or regulatory sequences important for the translation of the DLL4 mRNA.

Indeed, according to the prediction, the 320-nucleotide-long human DLL4 5'-UTR is highly structured (Figure S1B) due to a high percentage of $\mathrm{G}$ and $\mathrm{C}$ residues (more than $70 \%$ ). Analysis by the MFold prediction algorithm revealed that the full human DLL4 5'-UTR form a free energy structure of less than $-150 \mathrm{kcal} / \mathrm{mol}$, but also that the first 85 bases of the human DLL4 mRNA might form a very stable secondary structure $(\Delta \mathrm{G}=-37.2 \mathrm{kcal} / \mathrm{mol})$ (Figure $\mathrm{S} 1 \mathrm{~B})$. Secondary structural features of the mRNA $5^{\prime}$-untranslated region (UTR) are important for translational regulation by affecting the recruitment and positioning of the ribosome at a favorable initiation codon [31,32], and both thermal stability and cap-to-hairpin proximity affect translational efficiency, particularly when the predicted hairpin stability is below $-25 \mathrm{kcal} / \mathrm{mol}$ [33]. These structural elements act as strong barriers to scanning ribosomes in the $5^{\prime}$-UTR of mRNAs and are incompatible with the conventional scanning initiation model. In general, the corresponding mRNAs have evolved nonconventional mechanisms to initiate translation, including IRES elements, which are specialized RNA regulatory sequences governing cap-independent translational initiation. A typical example is the Ornithine Decarboxylase (ODC) mRNA, which possesses, in the cap proximal part, a very stable stem-loop structure highly inhibitory of cap-dependent translation [34] but also an IRES element allowing an efficient translation of this mRNA [35].

Thus, we first investigated whether the DLL4 5'-UTR contained any IRES activity. In this aim, a classical bicistronic reporter plasmid was constructed by the insertion of a cDNA corresponding to the DLL4 5'-UTR (nts 1 to 320) between two reporter gene sequences, the first encoding Renilla Luciferase which is strictly dependent upon cap-dependent translation, and the second encoding Firefly Luciferase which is dependent upon the presence of an IRES for its translation (Figure 1A) [36,37]. Twenty-four hours after transfection into HUVEC, HeLa and NIH-3T3 cells, Renilla and Firefly activities were measured and the LucF (Firefly)/LucR (Renilla) ratios were calculated as an index of IRES/Cap-dependent translation (Figure 1B-D). The EMCV and VEGF constructs containing IRES were used as positive controls [4,38], and the FGF-1A construct was used as a negative control since although it contains an IRES, its activity is cell type-dependent [39]. Our results showed that DLL4 5'-UTR contained a putative IRES with an activity comparable to that of VEGF- $A$ in the three cell lines tested (Figure 1B-D). To rule out the possibility of the presence of a cryptic promoter in the DLL4 5'-UTR, which could also cause Firefly activity, we cloned the DLL4 5'-UTR in the Tet-Off bicistronic system [2]. In this system, the bicistronic cassette is under the control of a doxycycline-repressible promoter (Figure 1E). Thus the LucF/LucR ratio is expected to be stable and independent of the CMV-driven expression level if expression of the second cistron is IRES dependent. In contrast, if there is an intercistronic cryptic promoter, LucF expression will be independent of the CMV promoter, and thus the LucF/LucR ratio will increase proportionally to the repression of CMV promoter by doxycycline. The individual two VEGF IRESes, known to be promoterless, and the full length $5^{\prime}-V E G F-A 5^{\prime}-\mathrm{UTR}$, known to contain a promoter, were used as controls [2]. The results clearly show that the LucF/LucR 
ratio increased with the inactivation of the $\mathrm{CMV} /$ Tet promoter after doxycycline treatment when the full VEGF-A $5^{\prime}$-UTR was present between the two cistrons. In contrast, the ratios remained unchanged when the individual VEGF IRESes or the DLL4 5'-UTR were tested, demonstrating the absence of cryptic promoter in the intercistronic region. Altogether these results indicate that the DLL4 $5^{\prime}$-UTR possesses an IRES that can initiate cap-independent translation.
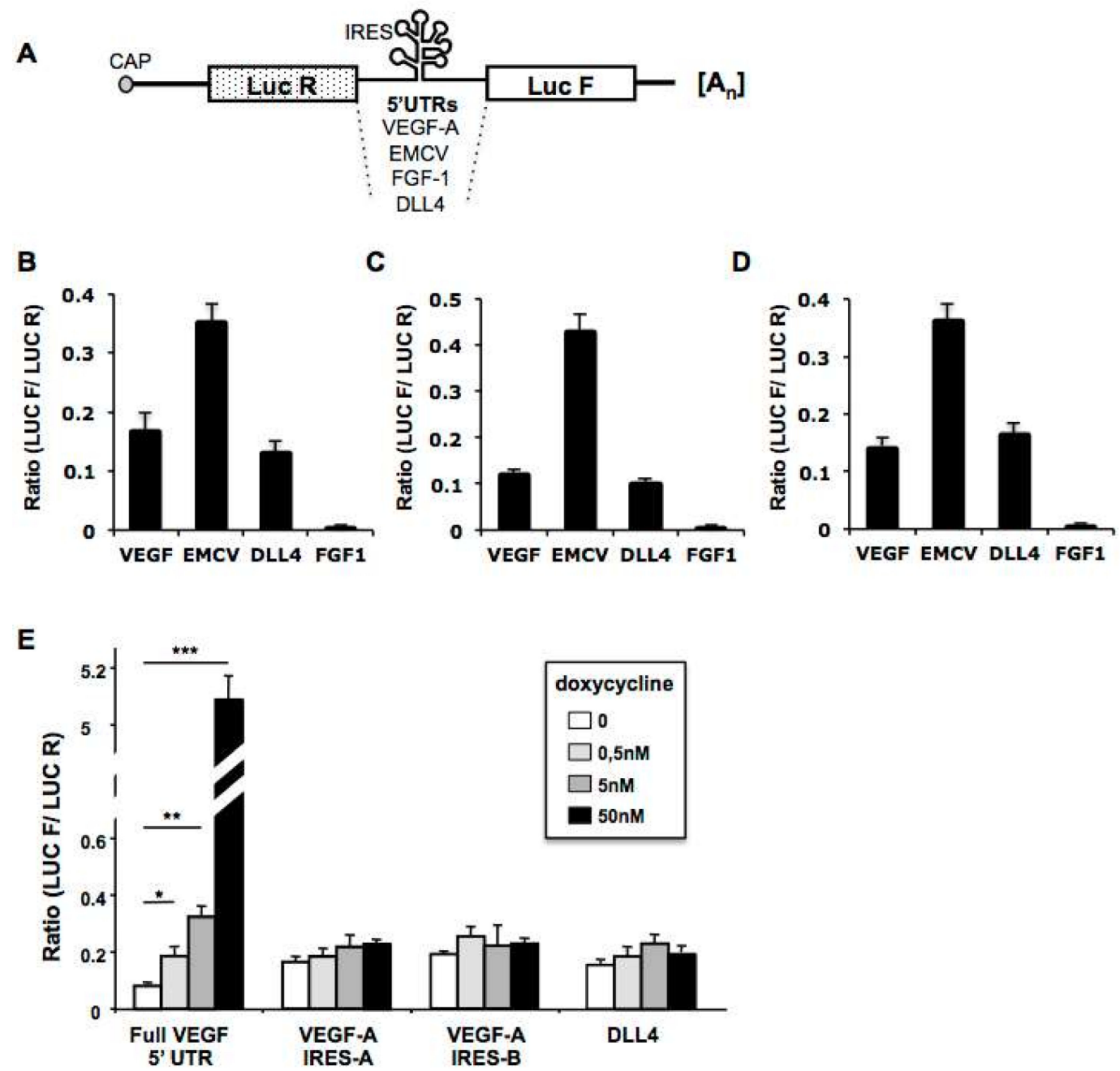

Figure 1. DLL4 $5^{\prime}$-UTR contains an internal ribosome entry site. (A) Schematic representation of bicistronic constructs. IRESs cloned within the inter-cistronic region were either viral $(E M C V)$ or cellular (VEGF-A IRESA, VEGF-A IRESB, FGF-1, DLL4), (B-D) Analysis of the DLL4 IRES activity in transiently transfected (B) HeLa, (C) HUVEC or (D) NIH3T3 cells. 48h after transfection IRES activity was determined by calculating the LucF/LucR ratio. DLL4 IRES activity was compared to that of the cellular IRES-A of VEGF-A, the viral EMCV IRES or the FGF-1A IRES, known to be highly tissue and cell line specific. (E) HeLa Tet off cells were transfected with TET sensitive bicistronic constructs containing the full $5^{\prime}$-untranslated region of DLL4. At $2 \mathrm{~h}$ prior to transfection, cells were treated with $0.5 \mathrm{nM}, 5 \mathrm{nM}$ or $50 \mathrm{nM}$ doxycycline (Dox). Forty-eight hours after transfection, luciferase activities were measured as described. As positive controls, the VEGF- $A$ full $5^{\prime}$-UTR (containing a cryptic promoter) was introduced in the intercistronic region and only the VEGF-A IRES A or $\mathrm{B}$ as negative controls (sequences without cryptic promoter). Data are means \pm SEM from 3 independent experiments in duplicates, ${ }^{*} p<0.05,{ }^{* *} p<0.01,{ }^{* * *} p<0.001$.

\subsection{DLL4 IRES Activity is Stimulated by Hypoxia}

Given that DLL4 is mainly expressed by the tip cells, localized at the leading edge of vessel sprouts in an unfavorable hypoxic microenvironment, we next tested the effect of hypoxia on the DLL4 
IRES activity (Figure 2). Bicistronic constructs were transfected in HeLa and HUVEC cells. As expected, under hypoxic conditions HIF1 $\alpha$ expression increased and Eukaryotic Initiation Factor 4E-Binding Protein 1 (4E-BP1) was dephosphorylated (shift to a band of lower apparent molecular weight in western blot) (Figure 2A,C). In the meantime we observed the inhibition of cap-dependent translation (decreased LucR activity) and no effect on LucF activity driven by EMCV IRES, while the DLL4 IRES-driven expression of LucF increased in both cell types after hypoxia (Figure 2B,D). Hypoxic stress resulted in a 2.5-fold stimulation of DLL4 IRES activity whereas EMCV IRES-mediated translation (LucF activity) remains stable in the two cell types (Figure 2B,D).

These results confirm the presence of a bona fide IRES element in the $5^{\prime}$-UTR of DLL4 mRNA, which is activated under hypoxia.

A

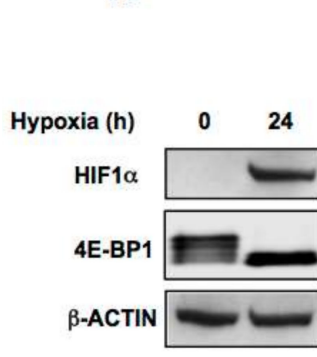

C

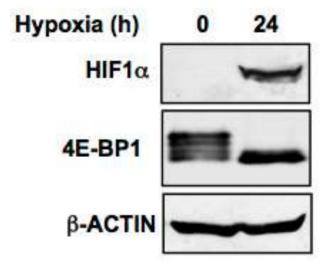

B
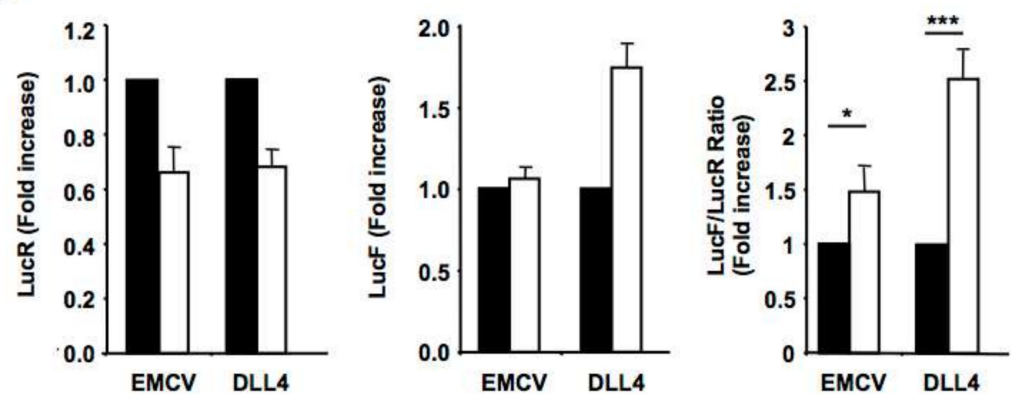

D

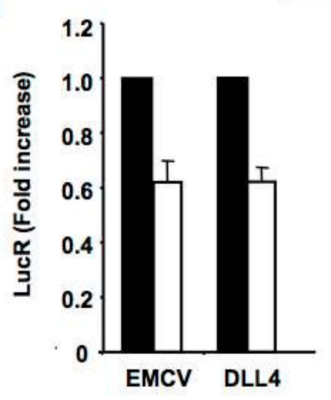

\section{Normoxia $\square$ Hypoxia}

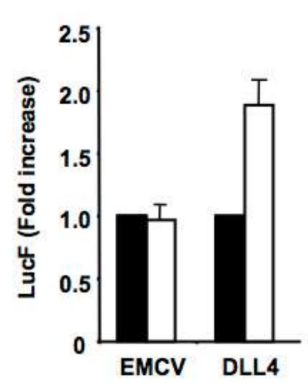

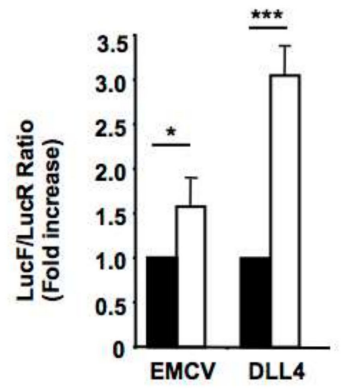

Figure 2. The DLL4 IRES is activated by hypoxia. HeLa (A,B) or HUVEC endothelial cells (C,D) cells were transfected by bicistronic constructs containing either the EMCV or the DLL4 IRES and submitted to $24 \mathrm{~h}$ hypoxia. $(\mathbf{A}, \mathbf{C})$ Hypoxia was confirmed through verifying both expression induction of HIF- $1 \alpha$ and $4 \mathrm{E}-\mathrm{BP} 1$ dephosphorylation (lower band visible at $24 \mathrm{~h}$ of hypoxia) by western blotting. $\beta$-ACTIN was used as a loading control. (B,D) Relative luciferase activities LucR, LucF or LucF/LucFR ratio (fold increase) under normoxia (black bars) and hypoxia (white bars) in HeLa (B) or HUVEC (D) cells. Results represent the means of three independent experiments $( \pm \mathrm{SEM}){ }^{*} p<0.05,{ }^{* * *} p<0.001$.

\subsection{The DLL4 IRES is Stimulated Following ER Stress}

Many cellular stresses, including hypoxia, can activate ER dependent pathways by inducing an accumulation of misfolded/unfolded proteins within the ER [4,40]. In order to investigate whether the DLL4 IRES responds to ER stress, we transfected HeLa cells with constructs containing the EMCV, or the DLL4 IRES and treated them for $4 \mathrm{~h}$ with increasing amounts of dithiothreitol (DTT) a well-known ER stress inducer (Figure 3). To confirm ER stress activation we verified the increased levels of both XBP1 splicing by RT-PCR and phospho-eIF2 $\alpha$ (p-eIF2 $\alpha$ ) by western blotting after DTT treatment (Figure 3A). By comparing the ratio of luciferase reporter activities $(\mathrm{LucF} / \mathrm{LucR})$ between treated and control cells, we found that the relative DLL4 IRES activity was around 5-fold greater in cells treated with $8 \mathrm{mM}$ DTT for $4 \mathrm{~h}$ versus control cells (Figure 3B). On the contrary, and as previously described, the EMCV IRES was not activated under the same conditions $[4,40]$. As expected, triggering of ER stress resulted 
in a decrease of LucR expression in a dose-dependent manner after DTT, given its inhibitory effect on cap-dependent translation [4,40]. Interestingly, whereas the EMCV IRES-mediated expression of the second cistron encoding LucF also diminished dose-dependently, the LucF expression driven by the DLL4 IRES increased after DTT treatment (Figure 3B). These results demonstrate that the DLL4 IRES is activated by ER stress. Furthermore, during ER stress, DLL4 cap-independent translation is increased when global cap-dependent translation is repressed.

A
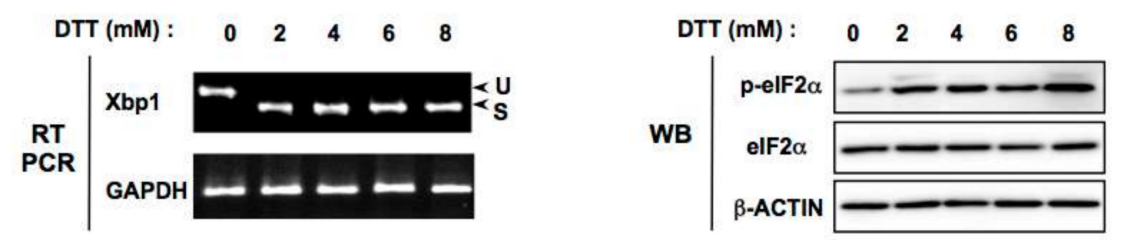

B

\begin{tabular}{|l}
$\square \mathrm{NT}$ \\
\hline
\end{tabular}

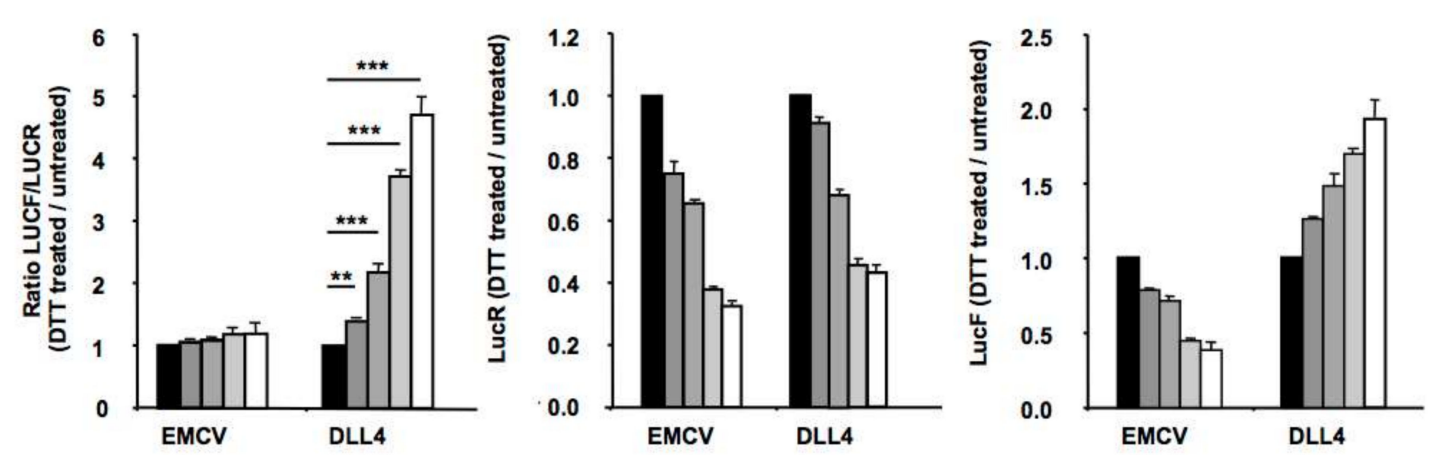

Figure 3. The DLL4 IRES is activated by ER stress. HeLa cells were transfected by bicistronic constructs containing either the EMCV or the DLL4 IRES and treated or not for $6 \mathrm{~h}$ with increasing concentrations of DTT. (A) ER stress induction was verified by monitoring both cytoplasmic XBP1 splicing by RT-PCR and eIF2 phosphorylation by western blotting (B) Relative luciferase activities (LucR, LucF or LucF/LucR ratio) after ER stress induction by treatment with increasing amounts of DTT for $6 \mathrm{~h}$. IRES activities were determined by calculating the LucF/LucR ratios and are expressed as fold change versus untreated cells. The results represent the means of three independent experiments $( \pm \mathrm{SEM}),{ }^{* *} p<0.01,{ }^{* * *} p<0.001$.

\subsection{PERK Kinase is Required for DLL4 IRES-Mediated Translational Upregulation During ER Stress in Vitro}

In response to ER stress, cells activate the physiological unfolded protein response (UPR) triggered by the activation of three ER transmembrane sensors: PKR-like ER-associated protein kinase (PERK), Activating Transcription Factor-6 (ATF6) and Inositol-Requiring Enzyme-1 (IRE1) [41,42]. To investigate the pathways involved in DLL4 IRES activation during ER stress, we down-regulated the expression of these three ER stress sensors in HeLa cells. Transient downregulation of PERK, ATF6 and IRE1 by siRNA interference was confirmed by western blotting or semi-quantitative RT-PCR (Figure 4A). After DTT treatment, the phosphorylation of eIF2 $\alpha$ was, as expected, diminished in cells transfected with PERK siRNA as was XBP-1 splicing after transfection of IRE1 siRNA (Figure 4B). We then co-transfected the bicistronic constructs with the respective siRNAs and calculated the ratio of IRES activities (LucF/LucR) between cells treated or not with DTT. The down-regulation of the three ER-stress transducers had no effect on EMCV IRES activity after DTT treatment (Figure 4C). On the other hand, ER stress-induced stimulation of the DLL4 IRES was only affected after PERK down-regulation, suggesting that PERK, but not IRE1 or ATF6, is required for the control of DLL4 IRES activity. 
A

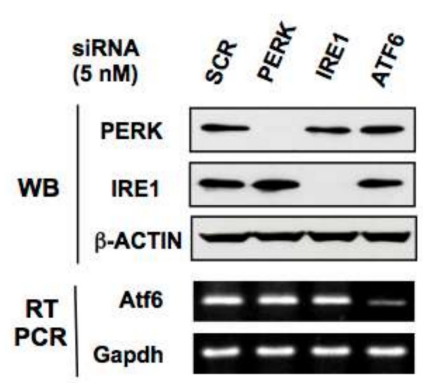

B

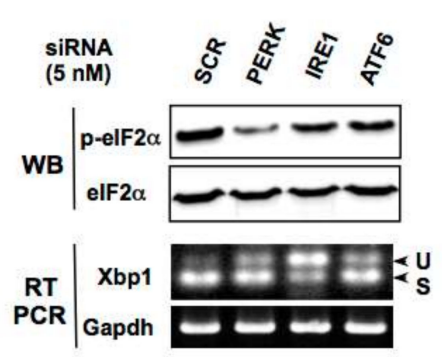

C

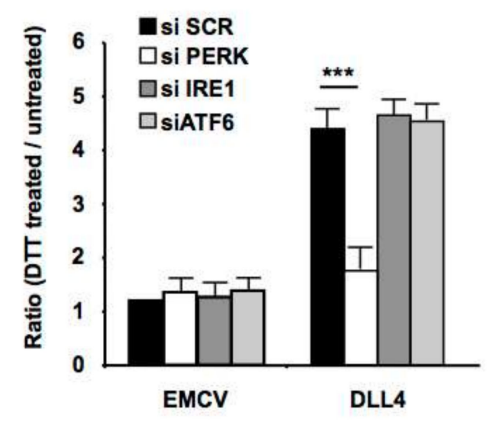

$\mathbf{F}$

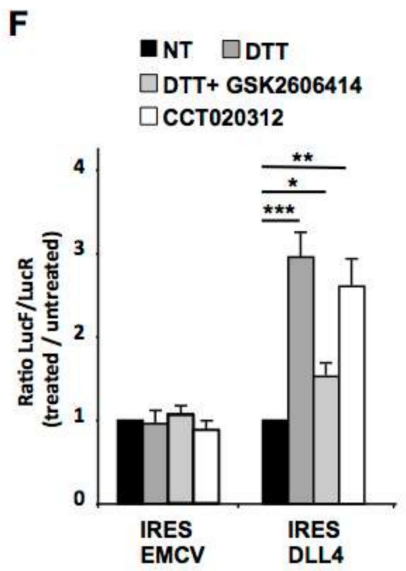

Figure 4. Role of three UPR sensors in DLL4 IRES translation activation by ER Stress. (A) HeLa cells were transfected with PERK, ATF6, IRE1 or control (Scr) siRNA. The knockdown efficiency of the targeted transcripts was determined by western blotting with PERK, IRE1 and $\beta$-ACTIN antibodies, and by semi-quantitative RT-PCR against ATF6 and GAPDH as a control. (B) Western blot analysis of phosphorylated eIF2 $\alpha$ and total eIF2 $\alpha$ and RT-PCR analysis of XBP1 splicing performed after transfection of HeLa cells either with siRNA specific for PERK, ATF6, or IRE1 or with control siRNA (Scr), after treatment with DTT. (C) Relative IRES activities in HeLa cells treated with DTT/control after co-transfection with siRNA specific for PERK, ATF6 or IRE1, or with control siRNA (scr) and DLL4 or EMCV bicistronic vectors. (D) Western blot analysis of phosphorylated eIF2 $\alpha$ and total eIF2 $\alpha$ and RT-PCR analysis of XBP1 splicing performed after transfection of HeLa cells with DLL4 or EMCV bicistronic vectors, after treatment with DTT and increasing concentration of the PERK inhibitor GSK2606414. (E) Western blot analysis of phosphorylated eIF2 $\alpha$ and total eIF2 $\alpha$ and RT-PCR analysis of XBP1 splicing performed after transfection of HeLa cells with DLL4 or EMCV bicistronic vectors, after treatment with increasing concentration of the PERK activator CCT020312. (F) Relative IRES activities in HeLa cells treated with DTT/control after transfection with DLL4 or EMCV bicistronic vectors and treatment with PERK activator (CCT020312) or inhibitor (GSK2606414). The results represent the means of three independent experiments $( \pm \mathrm{SEM}),{ }^{*} p<0.05,{ }^{* *} p<0.01,{ }^{* * *} p<0.001$.

Similar results were obtained after both specific pharmacological PERK activation with CCT020312 or inhibition with GSK2606414 during ER stress (Figure 4D-F). As expected, PERK inhibition by GSK2606414, which had no effect on the XBP1 splicing efficiency, prevented DTT-induced eIF2 $\alpha$ phosphorylation (Figure 4D), whilst PERK activation by CCT020312, which does not initiate cytoplasmic XBP1 splicing as opposed to DTT, stimulated eIF2 $\alpha$ phosphorylation (Figure 4E). Consistently, the inhibition or activation of PERK affected the DLL4 IRES (Figure 4F), whereas no effect on EMCV IRES activity was observed. Taken together, these results indicate that PERK activation is sufficient to stimulate DLL4 IRES activity. 
To complement the pharmacological approach, we used an already described inducible tetracycline/leucine zipper-based dimerization system enabling artificial activation of the PERK pathway [4,40]. In this model the intraluminal ER sensor domain of PERK is replaced by a c-Jun leucine zipper fused to a HA tag (PERK-LZ; Figure 5A). Thus, the addition of increasing concentrations of doxycycline induces specific expression and subsequent dimerization and activation of PERK-LZ as visualized by concomitant expression of the PERK-LZ (HA) expression and phosphorylation of eIF2 $\alpha$ (p-eIF2 $\alpha$ ) (Figure 5B). These cells were then used to confirm that selective PERK pathway activation was sufficient to stimulate DLL4 IRES activity. Forty-eight hours after the addition of $1 \mu \mathrm{g} / \mathrm{mL}$ doxycycline to the culture medium, cells were transfected with the bicistronic vectors containing the EMCV, and DLL4 5'-UTR IRES, and luciferase activities were measured $24 \mathrm{~h}$ later. An increase in IRES activity was seen with the DLL4 5'-UTR constructs but not with the construct containing the EMCV IRES (Figure 5C), further demonstrating that the PERK pathway is sufficient for DLL4 IRES activation during ER stress.

Finally, to investigate whether PERK alone is sufficient to induce DLL4 IRES activation or instead if signaling downstream PERK is required, we evaluated the effect of ATF4 (Activating Transcription Factor 4) down-regulation by siRNA on ER stress-induced DLL4 IRES activation. ATF4 regulates the transcription of a number of genes involved in stress response and cell survival and, in contrast to most transcripts, the translation of ATF4 is enhanced as a consequence of increased phosphorylation of eIF2 $\alpha$. siRNA-mediated ATF4 knockdown impaired neither eIF2 $\alpha$ phosphorylation nor PERK activation (shown by supershift in immunoblots of total PERK) (Figure 5D) and had no effect on the stimulation of DLL4 IRES after induction of ER stress by DTT (Figure 5E). This indicates that activation of the PERK pathway, independently of ATF4, is sufficient to stimulate DLL4 IRES activity.

To investigate the potential role of eIF2 $\alpha$ phosphorylation in this process we transfected bicistronic vectors in mouse embryo fibroblasts (MEFs) derived from either wild-type mice or from eIF $2 \alpha$ knock-in mice that have a homozygous mutation precluding eIF2 $\alpha$ phosphorylation (S51A). As expected, no phosphorylation of eIF2 $\alpha$ was observed in mutant MEFs after ER stress induction by DTT (Figure 5F) while this treatment efficiently induced a comparable XBP1 splicing in both S51A and WT MEFs (Figure 5F). The ratio of Firefly to Renilla luciferase between ER stress inducers treated and control cells remained stable with bicistronic vector containing the EMCV IRES and was significantly increased with the DLL4 IRES only in WT MEFs but not in S51A MEFs (Figure 5G). Taken together these results independently confirm that translation from DLL4 IRES is stimulated by PERK during ER stress, and demonstrate that phosphorylation of eIF $2 \alpha$ is required.

\section{5. hnRNP A1 Modulates DLL4 IRES-Mediated Translation}

IRES-dependent translation efficiency is controlled by RNA-binding proteins known as IRES trans-acting factors (ITAF). Subcellular relocalization of ITAFs plays a crucial role in the modulation of IRES-dependent translation efficiency [43]. Indeed, many RNA-binding proteins are able to shuttle between the nucleus and the cytoplasm. For example, it has been reported that cytoplasmic relocalization of ITAFs, such as hnRNPA1, may either activate or inhibit IRES activity when accumulating in the cytoplasm [44,45]. Interestingly, many stresses like UVC, osmotic shock or ER stress induce cytoplasmic hnRNPA1 relocalization [44-46]. Moreover, it was demonstrated that this hnRNPA1 cytoplasmic accumulation, during osmotic stress, requires eIF2 $\alpha$ phosphorylation [47]. 
A

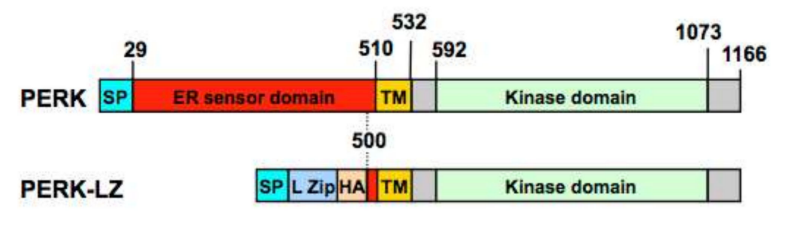

B

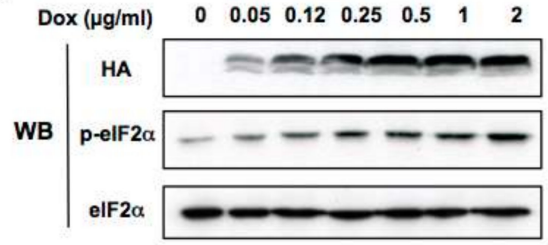

E

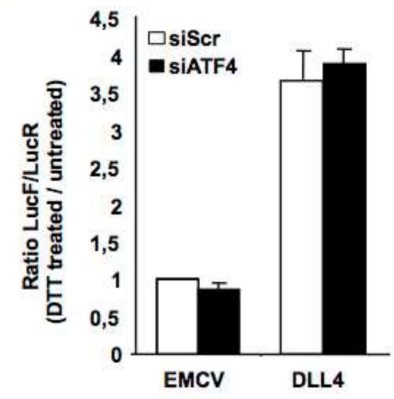

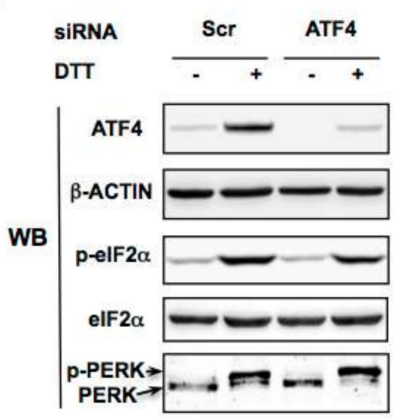

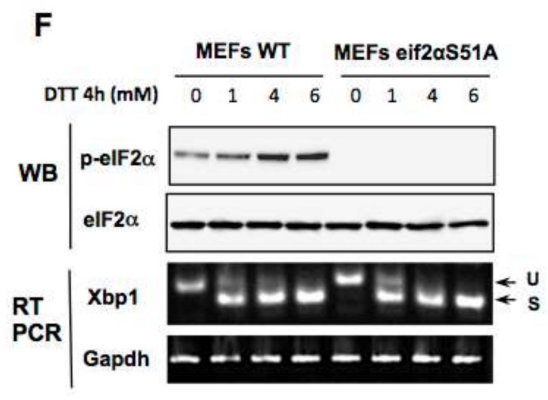

C

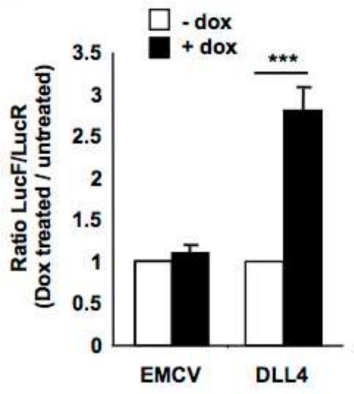

$\mathbf{F}$
G

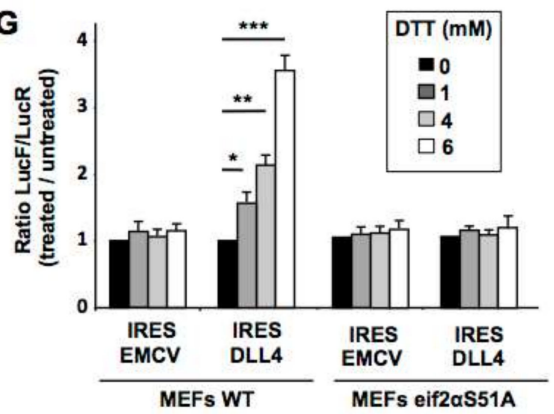

Figure 5. PERK kinase activity stimulates DLL4 IRES-mediated translation in a phosphorylated eIF2 $\alpha$-dependent manner. (A) Linear schematic representation of PERK and PERK-LZ showing the locations of the major functional domains (SP = Signal Peptide, L zip = Leucine Zipper, HA = HA Tag). Numbers indicate amino acid positions. (B) Western blot analysis of doxycycline-induced-PERK-LZ (HA) expression and eIF2 $\alpha$ phosphorylation after $48 \mathrm{~h}$ treatment with increasing amounts of doxycycline. (C) Relative IRES activities in PERK-LZ expressing HeLa cells treated with $1 \mu \mathrm{g} / \mathrm{mL}$ doxycycline / control after transfection of EMCV or DLL4 bicistronic vectors. Means \pm SEM are shown, ${ }^{* * *} p<0.001$. (D) Western blot analysis of ATF4, total and phosphorylated eIF2 $\alpha$, as well as total PERK in HeLa cells, after transfection with ATF4 or scramble (Scr) siRNA and treatment with DTT. $\beta$-ACTIN was used as a loading control. (E) Relative IRES activities in HeLa cells treated with DTT/control, after cotransfection with the EMCV or DLL4 bicistronic vectors and with either siRNA specific for ATF4 or control siRNA (Scr). Results represent the means of three independent experiments \pm SEM. (F) Wild-type (WT) and eIF2 $\alpha$ S51A MEFs transfected with the bicistronic LucR-IRES-LucF vectors and treated with increasing concentrations of DTT. ER stress induction was verified by monitoring eIF2 $\alpha$ phosphorylation by western blot and cytoplasmic XBP1 splicing by RT-PCR. (G) Relative IRES activities were determined as previously described in WT (left) and eIF2 $\alpha$ S51A (right) MEFs. Results represent the means of three independent experiments $\pm \mathrm{SEM},{ }^{*} p<0.05,{ }^{* *} p<0.01,{ }^{* * *} p<0.001$.

Thus we evaluated whether hnRNP A1 could play a role on the activation of DLL4 cap-independent translation after ER-stress-mediated eIF2 $\alpha$ phosphorylation. After verification of extraction efficiency of cytosolic and nuclear proteins in each fraction (Figure S2), we analyzed the nuclear and the cytosolic level of hnRNPA1 in DTT treated cells by western blotting experiments (Figure 6A). Results showed that hnRNPA1 level in the cytoplasm increased after $6 \mathrm{~h}$ of treatment with 
increasing concentrations of DTT, while the amount of hnRNPA1 in the nuclei decreased (Figure 6A), and the total hnRNPA1 level was not affected by the DTT treatment. To decipher the role of hnRNPA1 on the ER stress-mediated induction of DLL4 IRES activity, cells were co-transfected with the bicistronic constructs and either with scrambled or hnRNPA1-specific siRNA and ER stress was induced by DTT treatment. hnRNPA1 knockdown was efficient but did not impair eIF2 $\alpha$ phosphorylation after induction of ER stress by DTT (Figure 6B). While hnRNAP1 expression inhibition had no effect on EMCV IRES activity, it reduced DLL4 IRES activity during DTT-induced ER stress, compared to scramble siRNA transfected cells (Figure 6C). The data presented are consistent with a model in which DLL4 IRES activity is governed, at least in part, by the cellular IRES trans-acting factor hnRNPA1.

A

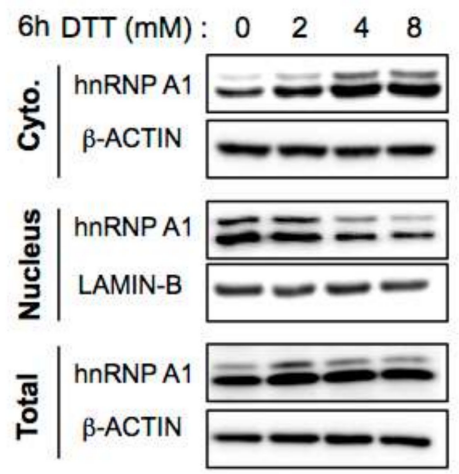

B

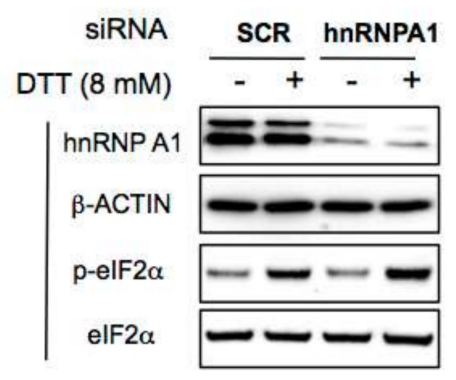

C $\operatorname{mDTT}_{\text {INTT }} \mid$ Scr siRNA ENT $\mid$ hnRNPA1 पDTT SiRNA

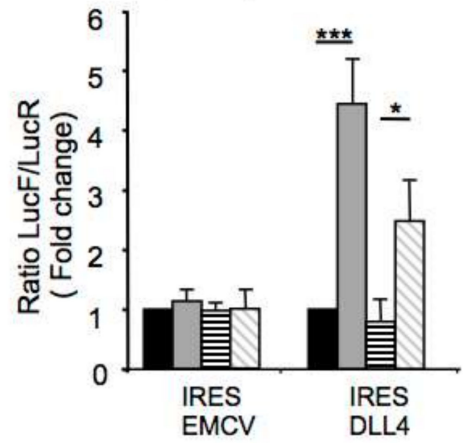

Figure 6. hnRNPA1 modulates DLL4 IRES activity during ER stress. (A) Western blot analysis of hnRNPA1 in HeLa nuclear, cytoplasmic or total extract after treatment with increasing concentrations of DTT. $\beta$-ACTIN was used as a loading control for cytoplasmic and total extracts and LAMIN-B for nuclear extract. (B) Western blot analysis of hnRNPA1, total and phosphorylated eIF2 in HeLa cells, after transfection with hnRNPA1 or scramble (Scr) siRNA and treatment with DTT. $\beta$-ACTIN was used as a loading control. (C) Relative IRES activities in HeLa cells treated with DTT/control, after cotransfection with the EMCV or DLL4 bicistronic vectors and with either siRNA specific for hnRNPA1 or control siRNA (Scr). Results represent the means of three independent experiments $\pm \mathrm{SEM} .{ }^{*} p<0.05$, *** $p<0.001$.

\section{Discussion}

Translational initiation is a well-established and crucial regulatory step of gene expression, allowing reprogramming of protein synthesis in response to environmental changes. Under stress conditions, the maintenance of routine translation machinery would be deleterious. Hence the synthesis of "housekeeping" proteins is paused in stressed cells whereas the translation of a pool of proteins necessary for the adaptive stress response is maintained, via alternative mechanisms of translational initiation. To bypass the stress-mediated inhibition of cap-dependent translation, more than 100 mammalian mRNAs harbor internal ribosome entry site (IRES) elements in their $5^{\prime}$-UTRs that mediate internal initiation of translation. These mRNA include many mRNA encoding proteins strongly involved in angiogenesis like VEGF-A, FGF-2, FGF-1A, VEGF-C, PDGF or TSP1 [48]. In this study we show that a bona fide IRES element is present in the 5'-UTR of DLL4 mRNA encoding the DLL4 protein that regulates angiogenesis during development, but also in pathological conditions, such as cancer $[16,20,26,49]$. Interestingly, as has already been shown for the VEGF and FGF-2 IRESs [2,4], the DLL4 IRES is activated under stress conditions including hypoxia and ER stress. This suggests that DLL4 remains efficiently translated during stress despite the substantial global inhibition of cap-dependent protein translation. We have also shown the significance of the PERK kinase in regulating stress-induced IRES-dependent translation of DLL4. Taken together our data suggest that DLL4 is translated under ER stress conditions despite phosphorylation of the major PERK substrate, 
eIF2 $\alpha$. It was previously demonstrated that PERK signaling is crucial for determining the growth and angiogenesis of specific tumors [50,51]. For example, UPR induced by glucose deprivation increases VEGF expression in human tissues in a PERK-dependent manner [52]. Moreover, tumors derived from K-Ras- transformed Perk - / - MEFs were found to be smaller than those derived from MEFs with an intact integrated stress response, because targeting PERK signaling disrupts angiogenic signals and prevents the appropriate organization and maturation of functional vessels [51].

This finding has biological relevance because several components involved in the same mechanism are translated in an IRES-dependent manner, providing selective co-regulation under stress conditions (Figure 7). Indeed, during tumor progression, the stress area encompasses both the tumor and its microenvironment. The growing neovessels that are inefficiently perfused, and more particularly TIP cells which are furthest away from the circulating blood, are also subjected to stress due to the unfavorable environment (hypoxia, glucose or amino acid starvation, acidosis). These adverse conditions are known to induce ER stress leading to eIF2 $\alpha$ phosphorylation and thus to activation of a network of genes dependent on ER stress. Many genes whose product are involved in angiogenesis, including Vegf- $a$, Fgf-2, Hif1 $\alpha$ and Dll4, and expressed either by tumoral cells or by the microenvironment, contain IRES element allowing the maintenance of an efficient translation of these mRNAs under stressful conditions while cap-dependent initiation is compromised (Figure 7). A number of other reports have demonstrated that IRES-dependent translation is driven by ER stress [4,40,53-55]. However, our results clearly show the link between the UPR, more precisely PERK/ eIF2 $\alpha$ signaling, and IRES-dependent translation of angiogenesis related genes. The physiological relevance of IRES-dependent translation mechanisms of non-viral mRNA is poorly documented in the literature and the precise mechanism of how stress signals downstream of eIF2 $\alpha$ phosphorylation are transduced to IRES elements remains unknown.

It was previously largely described that upstream open reading frames (uORFs) are key regulators of mRNA translation upon eIF2 $\alpha$ phosphorylation. In the case of stress-induced eIF $2 \alpha$ phosphorylation, it was proposed that after having translated the uORF, recharging of the ribosome with active initiation factors (including the ternary complex eIF2.GTP.met-tRNA) is the limiting step for reinitiating translation [56]. This model account for the observed increased translation efficiency of the downstream open reading frame when the intercistronic region is longer. The hypothesis is that when the region to be scanned is long, the ribosome would have enough time to reacquire reinitiation factors before encountering the downstream initiation codon. Nevertheless, DLL4 5'-UTR which is highly GC rich, doesn't contain uORF.

Moreover, secondary structures, which could be stabilized by specific protein binding, could slow down scanning of the $43 \mathrm{~S}$ pre-initiation complex and by this way increase translation reinitiation efficiency [57]. All the cellular IRESs already characterized used the so-called "land and scan" mechanism to initiate translation. The $40 S$ subunit associates with the IRES upstream of the initiation codon, and then scan the mRNA in a 5'-to-3' direction until start codon recognition occurs [58-60]. The presence in IRES elements of extensive secondary structure, representing a significant barrier slowing down the ribosome scanning, could explain the need of IRES mediated translation under stress conditions when eIF $2 \alpha$ is phosphorylated. We can also postulate that the presence of pause sites within the IRES sequence scanned by the ribosome, will allow it to reacquire active initiation factors and to initiate efficiently the translation at the downstream AUG. This hypothesis is supported by the fact that for EMCV IRES which is insensitive to ER stress, there is good evidence that the $40 \mathrm{~S}$ ribosomal subunits associated with initiation factors bind directly to the initiating AUG without any scanning requirement [61]. Indeed, it was demonstrated that eIF2 was necessary for EMCV mRNA translation [62] and that either treatment stimulating PKR (RNA-dependent protein kinase R, one of the four known eIF2 $\alpha$ kinases) or activation of PKR alone suffices to block EMCV translation [63,64] confirming that EMCV IRES activity was inhibited upon eIF2 $\alpha$ phosphorylation. 


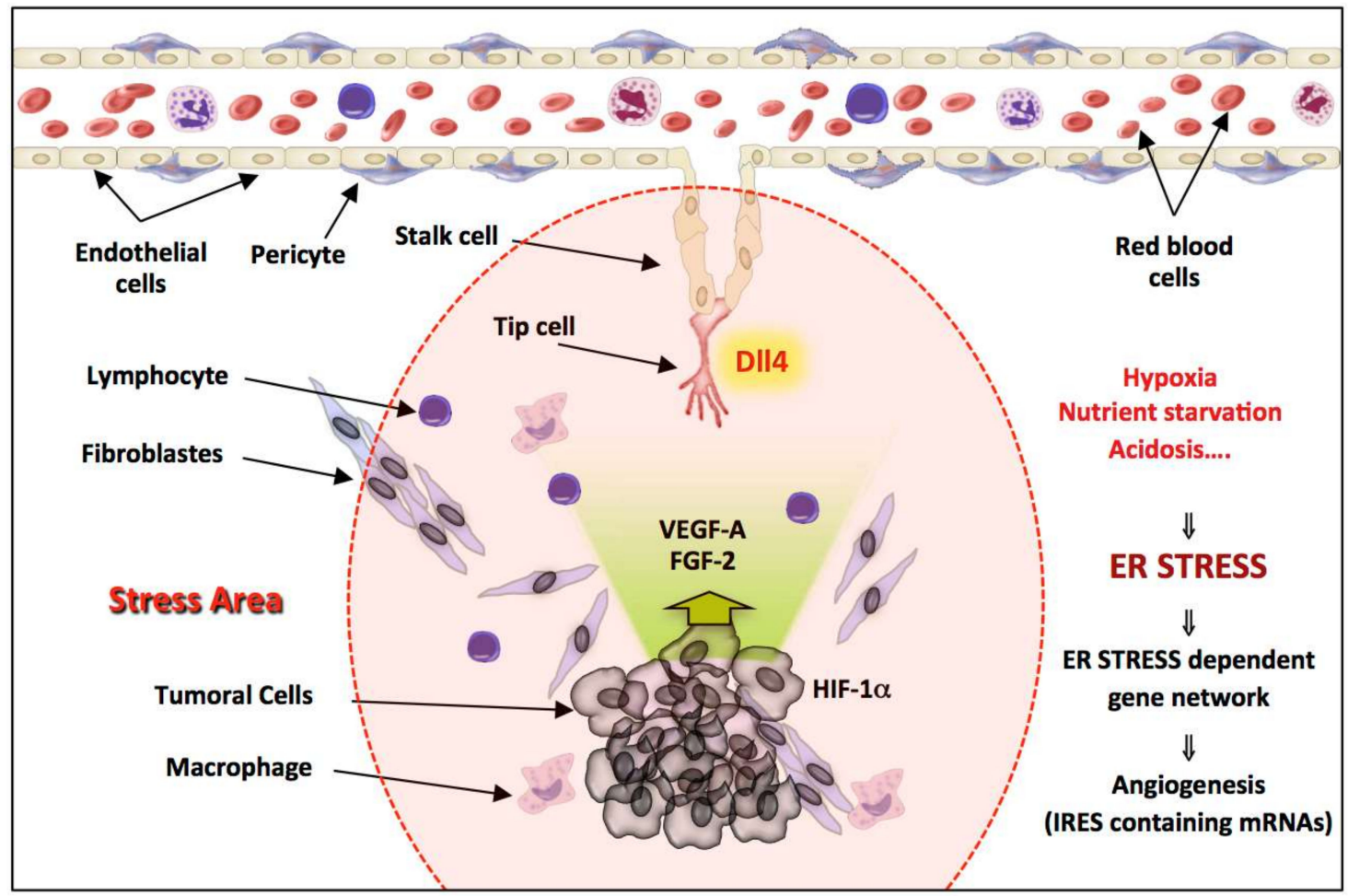

Figure 7. Schematic model of the network of gene expression co-regulation by stress during tumoral progression. During tumor progression, the stress zone encompasses the growing tumor, but also its microenvironment. The neo vessels and more particularly the Tip cells, present at the extremity and which guide the neo vessels towards the tumor, are located in this unfavorable microenvironment. Hypoxia, nutrient starvation and acidosis will irremediably induce the accumulation of unfolded protein in the reticulum of cells located in this area, leading to ER stress and UPR activation. Thus, in addition to transcriptional regulations, the activation of the PERK pathway will induce the co-regulation of an UPR dependent gene network containing IRES elements, revealing a translational regulon in which the synthesis of a cohort of angiogenic related genes is activated in response to ER stress. The fine-tuning of gene expression allows an efficient control of angiogenesis, which is a highly regulated process.

Emerging evidence has shown that the ribosome itself can play a crucial role in the specialized translation of specific subsets of mRNAs harboring specific cis-regulatory elements. Ribosomal biogenesis involves hundreds accessory factors and requires transcriptional and post-transcriptional steps which are timely and spatially regulated. It is thus not surprising that alteration of ribosome biogenesis is associated with dysregulation of translational efficiency. During hypoxic stress for example, cells maintained viability by restricting ribosomal biogenesis, the most energy-demanding cellular process [65]. We can hypothesize that cap-independent translation through the use of IRES elements is a mechanism, which is favored by low ribosome content during stress conditions. In the same vein, recent evidence suggests that ribosomal proteins themselves may function to recognize specific IRES elements. For example RPS19 and RPL11 regulate IRES-dependent translation of BCL-2-associated athanogene (BAG1) and cold shock domain containing protein E1 (CSDE1) [66].

Both the ribosomal RNA and proteins are heavily modified in mature ribosomes leading to ribosome heterogeneity that could be an important mechanism regulated during stress conditions. It was demonstrated that both 2'-O-methylation and hypo-pseudouridylation of rRNA is associated with impaired IRES-dependent translation $[67,68]$, and that ribosomes bound to the HCV IRES have a different methylation pattern from ribosomes bound to host mRNAs, indicating a role of methylated ribosomal proteins in IRES-mediated translational control [69]. Moreover, in mouse and human cells 
expressing a hypomorphic form of the pseudouridine synthase dyskerin, the translation of some IRES-containing mRNAs was impaired [68,70,71]. Likewise, yeast expressing a catalytically inactive form of $\mathrm{Cbf5}$, the homolog of human dyskerin, are also deficient in IRES dependent translation initiation [72]. However, it was also shown that dyskerin depletion increases VEGF mRNA internal ribosome entry site-mediated translation [73], indicating that cell type or genetic and environmental factors most certainly could influence the degree of implication of dyskerin in the translation of IRES containing mRNA. Given that hypoxic stress decreases dyskerin expression level [74], it would be of great interest to investigate the effect of ER stress or hypoxia on both ribosomal protein expression or rRNA modifications including 2'-O-methylation and pseudouridylation. Moreover, it will also be interesting to investigate whether ribosomal proteins promote specialized translation of IRES-containing mRNAs, either directly or through ITAFs. Indeed, many studies showed that ITAFs are able to stabilize the adequate RNA conformation allowing ribosome recruitment [75]. ITAFs are responsible for sensing changes in cellular metabolism and influence IRES activity. Moreover, subcellular distribution of many of them is modulated by stress [43]. Thus, both the expression level and localization of ITAFs could finely regulate the expression of IRES containing mRNAs. The results presented in this study suggest that the hnRNP A1 is an ITAF that increases the DLL4 IRES activity in stress conditions, and that this regulation is dependent on the nucleo-cytoplasmic relocation of hnRNP A1 upon ER stress. The same mechanism was already described for the cap independent translation of the transcription factor SREBP-1 (sterol-regulatory-element binding protein 1) during ER stress [75]. Nevertheless, we did not observe a complete inhibition in IRES-mediated translation after knockdown of hnRNP A1. The main reasons are the knockdown efficiency of hnRNP A1 by the siRNA (hnRNP A1 protein is abundant in the cell) and the potential presence of other ITAFs. Further investigation would be necessary to completely understand IRES-mediated translation of DLL4 mRNA.

\section{Materials and Methods}

\subsection{Plasmid Constructions and Viral Production}

The ER transmembrane and cytoplasmic domains of the human PERK protein were cloned from human cDNA using the PERKHALZ and PERK reverse primers (Table 1). Signal peptides and leucine zipper (LZ) peptides were merged with the PERK domains using the primers shown in Table 1.

Table 1. Oligonucleotide sequences.

\begin{tabular}{ll}
\hline Primer $\mathbf{N a m e}$ & ${\text { Sequence } \mathbf{5}^{\prime} \rightarrow \mathbf{3}^{\prime}}^{\prime}$ \\
\hline PERKHALZ & CAGCTCAAGACGCGTTTCGAATACCCATACGATGTTCCTGACTATGCGAGATTCCTCGACAACCCACA \\
\hline PERK rev & TTCTCGAGTATCGATTTACTAATTCTTGGCAAAGGGC \\
\hline SP & AAACTAGTGCCATGGCTCCGGCCCGCGGCTGCTGCTGCTGCTGACGCTGCTGCTGCCCGGCCT \\
\hline SP-LZ 1 & CACTTTCTCTTCCAGGCGCGATGTGCTGGTACTTCCAAAAATCCCGAGGCCGGGCAGCAGCAGCGT \\
\hline SP-LZ 2 & CGCGCCTGGAAGAGAAAGTGAAGACCCTCAAGAGTCAGAACACGGAGCTGGCGTCCACGGCGAGC \\
\hline LZ & TTCGAAACGCGTCTTGAGCTGCGCCACCTGCTCGCGCAGCAGGCTCGCCGTGGACGCCAGCTC \\
\hline XBP1-R & CTGGAACAGCAAGTGGTAGA \\
\hline DLL4+1-F & CTCCTCCAGGCTGGCAGG \\
\hline DLL4 ATG-R & AAACTAGTGCTGCGCGCAGGCCGGGAACACG \\
\hline GAPDH-F & CAAGGTCATCCATGACAACTTTG \\
\hline GAPDH-R & GTCCACCACCCTGTTGCTGTAG \\
\hline ATF6-F & GGGAGACACATTTTATGTTGTGTC \\
\hline ATF6-R & GGTTTGATTCCTCTGCTGATCTCG \\
\hline
\end{tabular}

Sequences were confirmed by DNA sequencing. Purified PCR products were digested with KpnI and XhoI restriction enzymes and inserted into the pTRIPz-TRE-Tigh plasmid (Open Biosystems, 
Dharmacon Lafayette, CO, USA) to generate the pL-TRE-PLZ expression vectors. Viruses were produced by transfecting HeLa cells $\left(5.0 \times 10^{4}\right)$ with the JetPEI transfection reagent (Polyplus Transfection, Illkirch, France), according to the manufacturer's instructions.

Constructs containing the VEGF-A, FGF-1A and EMCV IRESs have been previously described [4,37]. DLL4 5'-UTR was amplified by PCR using Phusion High-Fidelity (New England Biolabs, Evry, France) polymerase using the primers DLL4+1-F and DLL4 ATG-R. PCR product was subcloned into the $\mathrm{pCR}^{\mathrm{TM}}$-Blunt shuttle vector (Thermo Fisher Scientific, Dardilly, France), which was sequenced and then cloned into a bicistronic vector using the SpeI and NcoI restriction sites to give the pCRD4L vector. Constructs containing the VEGF- $A$ IRES A, B and the full VEGF 5'-UTR (namely pTCRVL) upstream of a tetracycline responsive promoter have been previously described [2]. After digestion of the PCRD4L by XbaI and PacI, the cassette LucR-5'-DLL4-LucF was inserted in the vector pTCRVL also digested by $\mathrm{XbaI}$ and PacI, thus replacing the VEGF sequence by the DLL4 one.

\subsection{Cell Culture and Transfection}

HeLa cells, NIH3T3 and both wild-type and eIF2 $\alpha$ S51A MEF cells (kindly provided by P. Fafournoux from INRA, Unité de nutrition Humaine, France) were cultivated in DMEM media (Sigma Aldrich, Saint-Quentin Fallavier France) supplemented with 10\% FCS, 1\% glutamine and antibiotics. Cells were transfected using the JetPEI transfection reagent (Polyplus Transfection), according to the manufacturer's instructions. 24 hours after transfection with the bicistronic constructs, cells were treated with DTT, the PERK activator CCT020312 (Merck Millipore, Fontenay sous Bois, France) or the PERK inhibitor GSK2606414 (Merck Millipore) for various concentrations, and were then harvested. For hypoxia, cells were incubated at $37^{\circ} \mathrm{C}$ at $1 \% \mathrm{O}_{2}$.

Human Umbilical Vein Endothelial Cells (HUVEC) pooled from 6 donors were prepared by digestion of umbilical veins with $0.1 \mathrm{~g} / \mathrm{L}$ collagenase A (Roche, Meylan, France) and cultivated in the specific Endothelial Cell Growth Medium 2 (PromoCell, Heidelberg Germany). Cells were transfected using the JetPEI-HUVEC transfection reagent (Polyplus Transfection), according to the manufacturer's instructions.

\subsection{Total RNA extraction and RT-PCR}

Total RNA was purified using the TRI Reagent solution (Applied Biosystems, Thermo Fisher Scientific, Dardilly, France)). Reverse transcription was carried out with $1 \mu \mathrm{g}$ of total RNA using a RevertAid First Strand cDNA Synthesis Kit (Thermo Fisher Scientific, Dardilly, France) with random hexamers, according to the manufacturer's instructions. The resulting cDNA was amplified by PCR for 30 cycles using Phusion High-Fidelity DNA Polymerase, $2 \times \operatorname{mix}$ (New England Biolabs) and specific primers (Table 1).

\subsection{Western Blot Analysis}

Western blotting was performed as previously described [76]. PERK, IRE1, ATF4, eIF4E-BP1, eIF2 $\alpha$ and p-eIF2 $\alpha$ were immunodetected using rabbit anti-human monoclonal antibodies (Cell Signaling, Danvers, MA, USA, dilution 1:1000) as the primary antibody, and peroxidase-conjugated sheep anti-rabbit (Cell Signaling Technology (Leiden, The Netherlands), dilution 1:5000) as secondary antibody. HA-tagged proteins and HIF- $1 \alpha$ were detected using the mouse monoclonal antibodies clone HA-7 (Sigma Aldrich) and Clone 54/HIF-1 $\alpha$ (BD Biosciences, Le Pont de Claix, France) respectively, and peroxidase-conjugated horse anti-mouse (Cell Signaling Technology, dilution 1:5000) as secondary antibody.

Protein signals were normalized using either total eIF $2 \alpha$ or an anti- $\beta$-actin monoclonal antibody (AC-15, Sigma-Aldrich (Saint-Quentin Fallavier France), dilution 1:10,000). Signals were detected using the Clarity chemiluminescence kit (Bio Rad, Marnes-la-Coquette, France). Nuclear and cytoplasmic extracts were obtained by using NE-PER ${ }^{\mathrm{TM}}$ Nuclear and Cytoplasmic Extraction Reagents (Thermo Fisher Scientific, Dardilly, France) according to the manufacturer's protocol. 


\subsection{RNA Interference}

RNA interference-mediated gene knockdown was achieved by transfecting $5 \mathrm{nM}$ of ATF6-, IRE1 $\alpha-$, PERK-, and ATF4-targeting or duplex control siRNA (ON-TARGETplus SMARTpool, Dharmacon, Lafayette, CO, USA) into HeLa cells using Interferin (Polyplus Transfection), according to the manufacturer's protocol. After 48 hours, cells were co-transfected ( $3 \mu \mathrm{g}$ plasmids and $5 \mathrm{nM}$ siRNA) with Lipofectamine 2000 (Invitrogen, Cergy-Pontoise, France), and harvested 24 hours later for protein and RNA analyses.

\subsection{Luciferase Activity}

For reporter vectors, luciferase activities were performed using Dual-Luciferase Reporter Assay (Promega, France). The quantification of Renilla and Firefly Luciferase activities was achieved $48 \mathrm{~h}$ after transfection with a luminometer (TriStar ${ }^{2}$ LB 942 Modular Multimode Microplate Reader, Berthold, Versailles, France), according to the manufacturer's instructions.

\subsection{Statistical Analyses}

All experimental data are expressed as mean \pm SEM and statistical significance was evaluated using Student's $t$-test. Differences were considered significant at values of $p<0.05\left({ }^{*} p<0.05\right.$; ${ }^{* *} p<0.01$; $* * * p<0.001)$.

\section{Conclusions}

In conclusion, DLL4 has evolved an IRES element that allows the enhancement of its translation under ER stress, a condition known to be activated during tumor development when the expression of this protein is crucial. The presence of IRES elements in many genes involved in angiogenesis and expressed in stress conditions including Fgf-2, vegf- $a$ or Hif1 $\alpha$ (Figure 7) and Dll4 suggest that IRESs function as cis-acting regulons during ER stress. In addition, we have shown the significance of the PERK kinase in regulating stress-induced IRES-dependent translation of this mRNA. These observations suggest that PERK could be a useful druggable target to control angiogenesis, possibly even locally, following an ischemic disorder or in cancers.

Supplementary Materials: The following are available online at http://www.mdpi.com/2072-6694/11/ 2/142/s1, Figure S1: (A) Partial alignment of the DLL4 mRNA 5'-untranslated region of several species. Conserved nucleotides are shown in red. Main DLL4 AUG translation initiation codon (on the right) is framed. (B) Example of RNA structure prediction by the RNAFold software (http://rna.tbi.univie.ac.at/cgibin/RNAWebSuite/RNAfold.cgi) of the first 85 nucleotides of the DLL4 5'-UTR and of the full DLL4 5'-UTR. Figure S2: Western blot analysis of $\beta$-ACTIN and LAMIN-B in HeLa nuclear and cytoplasmic extracts after treatment with increasing concentrations of DTT. $\beta$-ACTIN was mostly detected in the cytoplasmic fraction while LAMIN-B is exclusively present in the nuclear fraction.

Author Contributions: Conceptualization, H.L., S.P. and C.T.; Methodology, L.V.D.B., C.S. and L.M.; Formal Analysis, M.J., C.P., S.P., L.M., and C.T.; Investigation, M.J., C.P., L.M., H.L. and C.T.; Writing-Original Draft Preparation, S.P., and C.T.; Writing-Review \& Editing, L.M., S.P., H.L. and C.T.; Supervision, S.P., H.L. and C.T.; Funding Acquisition, C.T.

Funding: This work was supported by the Institut National de la Santé et de la Recherche Médicale (INSERM), Université Toulouse III (Paul Sabatier) and by research grants from La Ligue contre le Cancer. CP and MJ were supported by a fellowship from the French ministry of higher education and research.

Conflicts of Interest: The authors declare no conflict of interest.

\section{References}

1. Shing, Y.; Folkman, J.; Sullivan, R.; Butterfield, C.; Murray, J.; Klagsbrun, M. Heparin affinity: Purification of a tumor-derived capillary endothelial cell growth factor. Science 1984, 223, 1296-1299. [CrossRef]

2. Bornes, S.; Prado-Lourenco, L.; Bastide, A.; Zanibellato, C.; Iacovoni, J.S.; Lacazette, E.; Prats, A.C.; Touriol, C.; Prats, H. Translational induction of VEGF internal ribosome entry site elements during the early response to ischemic stress. Circ. Res. 2007, 100, 305-308. [CrossRef] [PubMed] 
3. Conte, C.; Riant, E.; Toutain, C.; Pujol, F.; Arnal, J.F.; Lenfant, F.; Prats, A.C. FGF2 translationally induced by hypoxia is involved in negative and positive feedback loops with HIF-1 $\alpha$. PLoS ONE 2008, 3, e3078. [CrossRef] [PubMed]

4. Philippe, C.; Dubrac, A.; Quelen, C.; Desquesnes, A.; Van Den Berghe, L.; Segura, C.; Filleron, T.; Pyronnet, S.; Prats, H.; Brousset, P.; et al. PERK mediates the ires-dependent translational activation of mrnas encoding angiogenic growth factors after ischemic stress. Sci. Signal. 2016, 9, ra44. [CrossRef] [PubMed]

5. Arcondeguy, T.; Lacazette, E.; Millevoi, S.; Prats, H.; Touriol, C. VEGF-A mRNA processing, stability and translation: A paradigm for intricate regulation of gene expression at the post-transcriptional level. Nucleic Acids Res. 2013, 41, 7997-8010. [CrossRef]

6. Takeuchi, H.; Haltiwanger, R.S. Role of glycosylation of Notch in development. Semin. Cell Dev. Biol. 2010, 21, 638-645. [CrossRef] [PubMed]

7. Gale, N.W.; Dominguez, M.G.; Noguera, I.; Pan, L.; Hughes, V.; Valenzuela, D.M.; Murphy, A.J.; Adams, N.C.; Lin, H.C.; Holash, J.; et al. Haploinsufficiency of delta-like 4 ligand results in embryonic lethality due to major defects in arterial and vascular development. Proc. Natl. Acad. Sci. USA 2004, 101, 15949-15954. [CrossRef]

8. Mailhos, C.; Modlich, U.; Lewis, J.; Harris, A.; Bicknell, R.; Ish-Horowicz, D. DELTA4, an endothelial specific NOTCH ligand expressed at sites of physiological and tumor angiogenesis. Differ. Res. Biol. Divers. 2001, 69, 135-144. [CrossRef]

9. Scehnet, J.S.; Jiang, W.; Kumar, S.R.; Krasnoperov, V.; Trindade, A.; Benedito, R.; Djokovic, D.; Borges, C.; Ley, E.J.; Duarte, A.; et al. Inhibition of DLL4-mediated signaling induces proliferation of immature vessels and results in poor tissue perfusion. Blood 2007, 109, 4753-4760. [CrossRef]

10. Eilken, H.M.; Adams, R.H. Dynamics of endothelial cell behavior in sprouting angiogenesis. Curr. Opin. Cell Biol. 2010, 22, 617-625. [CrossRef]

11. Leslie, J.D.; Ariza-McNaughton, L.; Bermange, A.L.; McAdow, R.; Johnson, S.L.; Lewis, J. Endothelial signalling by the NOTCH ligand Delta-Like 4 restricts angiogenesis. Development 2007, 134, 839-844. [CrossRef] [PubMed]

12. Lobov, I.B.; Renard, R.A.; Papadopoulos, N.; Gale, N.W.; Thurston, G.; Yancopoulos, G.D.; Wiegand, S.J. Delta-like ligand 4 (DLL4) is induced by VEGF as a negative regulator of angiogenic sprouting. Proc. Natl. Acad. Sci. USA 2007, 104, 3219-3224. [CrossRef] [PubMed]

13. Potente, M.; Gerhardt, H.; Carmeliet, P. Basic and therapeutic aspects of angiogenesis. Cell 2011, 146, $873-887$. [CrossRef] [PubMed]

14. Siekmann, A.F.; Lawson, N.D. Notch signalling limits angiogenic cell behaviour in developing zebrafish arteries. Nature 2007, 445, 781-784. [CrossRef] [PubMed]

15. Suchting, S.; Freitas, C.; le Noble, F.; Benedito, R.; Breant, C.; Duarte, A.; Eichmann, A. The NOTCH ligand Delta-Like 4 negatively regulates endothelial tip cell formation and vessel branching. Proc. Natl. Acad. Sci. USA 2007, 104, 3225-3230. [CrossRef] [PubMed]

16. Thurston, G.; Noguera-Troise, I.; Yancopoulos, G.D. The delta paradox: DLL4 blockade leads to more tumour vessels but less tumour growth. Nat. Rev. Cancer 2007, 7, 327-331. [CrossRef] [PubMed]

17. Gerhardt, H.; Golding, M.; Fruttiger, M.; Ruhrberg, C.; Lundkvist, A.; Abramsson, A.; Jeltsch, M.; Mitchell, C.; Alitalo, K.; Shima, D.; et al. Vegf guides angiogenic sprouting utilizing endothelial tip cell filopodia. J. Cell Biol. 2003, 161, 1163-1177. [CrossRef] [PubMed]

18. Hellstrom, M.; Phng, L.K.; Hofmann, J.J.; Wallgard, E.; Coultas, L.; Lindblom, P.; Alva, J.; Nilsson, A.K.; Karlsson, L.; Gaiano, N.; et al. DLL4 signalling through notch1 regulates formation of tip cells during angiogenesis. Nature 2007, 445, 776-780. [CrossRef] [PubMed]

19. Papetti, M.; Herman, I.M. Mechanisms of normal and tumor-derived angiogenesis. Am. J. Physiol. Cell Physiol. 2002, 282, C947-C970. [CrossRef] [PubMed]

20. Djokovic, D.; Trindade, A.; Gigante, J.; Badenes, M.; Silva, L.; Liu, R.; Li, X.; Gong, M.; Krasnoperov, V.; Gill, P.S.; et al. Combination of DLL4/NOTCH and EPHRIN-B2/EPHB4 targeted therapy is highly effective in disrupting tumor angiogenesis. BMC Cancer 2010, 10, 641. [CrossRef]

21. Carmeliet, P.; Ferreira, V.; Breier, G.; Pollefeyt, S.; Kieckens, L.; Gertsenstein, M.; Fahrig, M.; Vandenhoeck, A.; Harpal, K.; Eberhardt, C.; et al. Abnormal blood vessel development and lethality in embryos lacking a single vegf allele. Nature 1996, 380, 435-439. [CrossRef] [PubMed] 
22. Ferrara, N.; Carver-Moore, K.; Chen, H.; Dowd, M.; Lu, L.; O’Shea, K.S.; Powell-Braxton, L.; Hillan, K.J.; Moore, M.W. Heterozygous embryonic lethality induced by targeted inactivation of the vegf gene. Nature 1996, 380, 439-442. [CrossRef] [PubMed]

23. Patel, N.S.; Li, J.L.; Generali, D.; Poulsom, R.; Cranston, D.W.; Harris, A.L. Up-regulation of Delta-Like 4 Ligand in human tumor vasculature and the role of basal expression in endothelial cell function. Cancer Res. 2005, 65, 8690-8697. [CrossRef] [PubMed]

24. Simons, M.; Gordon, E.; Claesson-Welsh, L. Mechanisms and regulation of endothelial VEGF receptor signalling. Nat. Rev. Mol. Cell Biol. 2016, 17, 611-625. [CrossRef] [PubMed]

25. Diez, H.; Fischer, A.; Winkler, A.; Hu, C.J.; Hatzopoulos, A.K.; Breier, G.; Gessler, M. Hypoxia-mediated activation of DLL4-NOTCH-HEY2 signaling in endothelial progenitor cells and adoption of arterial cell fate. Exp. Cell Res. 2007, 313, 1-9. [CrossRef] [PubMed]

26. Jubb, A.M.; Turley, H.; Moeller, H.C.; Steers, G.; Han, C.; Li, J.L.; Leek, R.; Tan, E.Y.; Singh, B.; Mortensen, N.J.; et al. Expression of Delta-Like Ligand 4 (DLL4) and markers of hypoxia in colon cancer. Br. J. Cancer 2009, 101, 1749-1757. [CrossRef]

27. Li, Z.; Wang, J.; Gong, L.; Wen, Z.; Xu, C.; Huang, X. Correlation of Delta-Like Ligand 4 (DLL4) with VEGF and HIF-1alpha expression in human glioma. Asian Pac. J Cancer Prev. 2011, 12, 215-218. [PubMed]

28. Yu, S.; Sun, J.; Zhang, J.; Xu, X.; Li, H.; Shan, B.; Tian, T.; Wang, H.; Ma, D.; Ji, C. Aberrant expression and association of VEGF and DLL4/NOTCH pathway molecules under hypoxia in patients with lung cancer. Histol. Histopathol. 2013, 28, 277-284. [PubMed]

29. Zhang, J.X.; Cai, M.B.; Wang, X.P.; Duan, L.P.; Shao, Q.; Tong, Z.T.; Liao, D.Z.; Li, Y.Y.; Huang, M.Y.; Zeng, Y.X.; et al. Elevated DLL4 expression is correlated with VEGF and predicts poor prognosis of nasopharyngeal carcinoma. Med. Oncol. 2013, 30, 390. [CrossRef]

30. Duret, L.; Dorkeld, F.; Gautier, C. Strong conservation of non-coding sequences during vertebrates evolution: Potential involvement in post-transcriptional regulation of gene expression. Nucleic Acids Res. 1993, 21, 2315-2322. [CrossRef] [PubMed]

31. Gingras, A.C.; Raught, B.; Sonenberg, N. eIF4 initiation factors: Effectors of mRNA recruitment to ribosomes and regulators of translation. Annu. Rev. Biochem. 1999, 68, 913-963. [CrossRef] [PubMed]

32. Leppek, K.; Das, R.; Barna, M. Functional 5' UTR mRNA structures in eukaryotic translation regulation and how to find them. Nat. Rev. Mol. Cell Biol. 2018, 19, 158-174. [CrossRef] [PubMed]

33. Babendure, J.R.; Babendure, J.L.; Ding, J.H.; Tsien, R.Y. Control of mammalian translation by mRNA structure near caps. RNA 2006, 12, 851-861. [CrossRef]

34. Pyronnet, S.; Pradayrol, L.; Sonenberg, N. Alternative splicing facilitates internal ribosome entry on the ornithine decarboxylase mRNA. Cell. Mol. Life Sci. 2005, 62, 1267-1274. [CrossRef]

35. Pyronnet, S.; Pradayrol, L.; Sonenberg, N. A cell cycle-dependent internal ribosome entry site. Mol. Cell 2000, 5, 607-616. [CrossRef]

36. Bastide, A.; Karaa, Z.; Bornes, S.; Hieblot, C.; Lacazette, E.; Prats, H.; Touriol, C. An upstream open reading frame within an IRES controls expression of a specific VEGF-A isoform. Nucleic Acids Res. 2008, 36, 2434-2445. [CrossRef]

37. Bornes, S.; Boulard, M.; Hieblot, C.; Zanibellato, C.; Iacovoni, J.S.; Prats, H.; Touriol, C. Control of the vascular endothelial growth factor internal ribosome entry site (IRES) activity and translation initiation by alternatively spliced coding sequences. J. Biol. Chem. 2004, 279, 18717-18726. [CrossRef]

38. Karaa, Z.S.; Iacovoni, J.S.; Bastide, A.; Lacazette, E.; Touriol, C.; Prats, H. The VEGF IRESes are differentially susceptible to translation inhibition by miR-16. RNA 2009, 15, 249-254. [CrossRef]

39. Conte, C.; Ainaoui, N.; Delluc-Clavieres, A.; Khoury, M.P.; Azar, R.; Pujol, F.; Martineau, Y.; Pyronnet, S.; Prats, A.C. Fibroblast growth factor 1 induced during myogenesis by a transcription-translation coupling mechanism. Nucleic Acids Res. 2009, 37, 5267-5278. [CrossRef]

40. Bonnet-Magnaval, F.; Philippe, C.; Van Den Berghe, L.; Prats, H.; Touriol, C.; Lacazette, E. Hypoxia and ER stress promote STAUFEN1 expression through an alternative translation mechanism. Biochem. Biophys. Res. Commun. 2016, 479, 365-371. [CrossRef]

41. Chevet, E.; Hetz, C.; Samali, A. Endoplasmic reticulum stress-activated cell reprogramming in oncogenesis. Cancer Discov. 2015, 5, 586-597. [CrossRef] [PubMed]

42. Urra, H.; Hetz, C. Fine-tuning PERK signaling to control cell fate under stress. Nat. Struct. Mol. Biol. 2017, 24, 789-790. [CrossRef] [PubMed] 
43. Lewis, S.M.; Holcik, M. For IRES trans-acting factors, it is all about location. Oncogene 2008, 27, $1033-1035$. [CrossRef] [PubMed]

44. Damiano, F.; Rochira, A.; Tocci, R.; Alemanno, S.; Gnoni, A.; Siculella, L. HNRNP A1 mediates the activation of the IRES-dependent Srebp-1a mrna translation in response to endoplasmic reticulum stress. Biochem. J. 2013, 449, 543-553. [CrossRef] [PubMed]

45. Lewis, S.M.; Veyrier, A.; Hosszu Ungureanu, N.; Bonnal, S.; Vagner, S.; Holcik, M. Subcellular relocalization of a trans-acting factor regulates Xiap IRES-dependent translation. Mol. Biol. Cell 2007, 18, 1302-1311. [CrossRef] [PubMed]

46. Cammas, A.; Pileur, F.; Bonnal, S.; Lewis, S.M.; Leveque, N.; Holcik, M.; Vagner, S. Cytoplasmic relocalization of Heterogeneous nuclear ribonucleoprotein a1 controls translation initiation of specific mRNAs. Mol. Biol. Cell 2007, 18, 5048-5059. [CrossRef] [PubMed]

47. Bevilacqua, E.; Wang, X.; Majumder, M.; Gaccioli, F.; Yuan, C.L.; Wang, C.; Zhu, X.; Jordan, L.E.; Scheuner, D.; Kaufman, R.J.; et al. Eif2alpha phosphorylation tips the balance to apoptosis during osmotic stress. J. Biol. Chem. 2010, 285, 17098-17111. [CrossRef] [PubMed]

48. Mokrejs, M.; Masek, T.; Vopalensky, V.; Hlubucek, P.; Delbos, P.; Pospisek, M. Iresite-A tool for the examination of viral and cellular internal ribosome entry sites. Nucleic Acids Res. 2010, 38, D131-D136. [CrossRef] [PubMed]

49. Noguera-Troise, I.; Daly, C.; Papadopoulos, N.J.; Coetzee, S.; Boland, P.; Gale, N.W.; Lin, H.C.; Yancopoulos, G.D.; Thurston, G. Blockade of DLL4 inhibits tumour growth by promoting non-productive angiogenesis. Nature 2006, 444, 1032-1037. [CrossRef] [PubMed]

50. Bi, M.; Naczki, C.; Koritzinsky, M.; Fels, D.; Blais, J.; Hu, N.; Harding, H.; Novoa, I.; Varia, M.; Raleigh, J.; et al. ER stress-regulated translation increases tolerance to extreme hypoxia and promotes tumor growth. EMBO J. 2005, 24, 3470-3481. [CrossRef]

51. Blais, J.D.; Addison, C.L.; Edge, R.; Falls, T.; Zhao, H.; Wary, K.; Koumenis, C.; Harding, H.P.; Ron, D.; Holcik, M.; et al. PERK-dependent translational regulation promotes tumor cell adaptation and angiogenesis in response to hypoxic stress. Mol. Cell. Biol. 2006, 26, 9517-9532. [CrossRef] [PubMed]

52. Wang, Y.; Alam, G.N.; Ning, Y.; Visioli, F.; Dong, Z.; Nor, J.E.; Polverini, P.J. The unfolded protein response induces the angiogenic switch in human tumor cells through the PERK/ATF4 pathway. Cancer Res. 2012, 72, 5396-5406. [CrossRef] [PubMed]

53. Luo, X.N.; Song, Q.Q.; Yu, J.; Song, J.; Wang, X.L.; Xia, D.; Sun, P.; Han, J. Identification of the internal ribosome entry sites (IRES) of prion protein gene. Int. J. Biochem. Cell Biol. 2017, 93, 46-51. [CrossRef] [PubMed]

54. Graber, T.E.; Baird, S.D.; Kao, P.N.; Mathews, M.B.; Holcik, M. Nf45 functions as an IRES trans-acting factor that is required for translation of Ciap1 during the unfolded protein response. Cell Death Differ. 2010, 17, 719-729. [CrossRef] [PubMed]

55. Chan, C.P.; Kok, K.H.; Tang, H.M.; Wong, C.M.; Jin, D.Y. Internal ribosome entry site-mediated translational regulation of ATF4 splice variant in mammalian unfolded protein response. Biochim. Biophys. Acta 2013, 1833, 2165-2175. [CrossRef] [PubMed]

56. Morris, D.R.; Geballe, A.P. Upstream open reading frames as regulators of mRNA translation. Mol. Cell. Biol. 2000, 20, 8635-8642. [CrossRef] [PubMed]

57. Andreev, D.E.; O'Connor, P.B.; Loughran, G.; Dmitriev, S.E.; Baranov, P.V.; Shatsky, I.N. Insights into the mechanisms of eukaryotic translation gained with ribosome profiling. Nucleic Acids Res. 2017, 45, 513-526. [CrossRef] [PubMed]

58. Jopling, C.L.; Spriggs, K.A.; Mitchell, S.A.; Stoneley, M.; Willis, A.E. L-MYC protein synthesis is initiated by internal ribosome entry. RNA 2004, 10, 287-298. [CrossRef]

59. Le Quesne, J.P.; Stoneley, M.; Fraser, G.A.; Willis, A.E. Derivation of a structural model for the $c$-myc IRES. J. Mol. Biol. 2001, 310, 111-126. [CrossRef]

60. Mitchell, S.A.; Spriggs, K.A.; Coldwell, M.J.; Jackson, R.J.; Willis, A.E. The Apaf-1 internal ribosome entry segment attains the correct structural conformation for function via interactions with PTB and UNR. Mol. Cell 2003, 11, 757-771. [CrossRef]

61. Kaminski, A.; Belsham, G.J.; Jackson, R.J. Translation of encephalomyocarditis virus RNA: Parameters influencing the selection of the internal initiation site. EMBO J. 1994, 13, 1673-1681. [CrossRef] [PubMed] 
62. Schreier, M.H.; Staehelin, T. Initiation of eukaryotic protein synthesis: (met-tRNA f-40s ribosome) initiation complex catalysed by purified initiation factors in the absence of mRNA. Nat. New Biol. 1973, 242, 35-38. [CrossRef] [PubMed]

63. Meurs, E.F.; Watanabe, Y.; Kadereit, S.; Barber, G.N.; Katze, M.G.; Chong, K.; Williams, B.R.; Hovanessian, A.G. Constitutive expression of human double-stranded RNA-activated p68 kinase in murine cells mediates phosphorylation of eukaryotic initiation factor 2 and partial resistance to encephalomyocarditis virus growth. J. Virol. 1992, 66, 5805-5814. [PubMed]

64. Rice, A.P.; Duncan, R.; Hershey, J.W.; Kerr, I.M. Double-stranded RNA-dependent protein kinase and 2-5a system are both activated in interferon-treated, encephalomyocarditis virus-infected hela cells. J. Virol. 1985, 54, 894-898. [PubMed]

65. Mekhail, K.; Rivero-Lopez, L.; Khacho, M.; Lee, S. Restriction of rRNA synthesis by VHL maintains energy equilibrium under hypoxia. Cell Cycle 2006, 5, 2401-2413. [CrossRef] [PubMed]

66. Horos, R.; Ijspeert, H.; Pospisilova, D.; Sendtner, R.; Andrieu-Soler, C.; Taskesen, E.; Nieradka, A.; Cmejla, R.; Sendtner, M.; Touw, I.P.; et al. Ribosomal deficiencies in diamond-blackfan anemia impair translation of transcripts essential for differentiation of murine and human erythroblasts. Blood 2012, 119, 262-272. [CrossRef] [PubMed]

67. Marcel, V.; Ghayad, S.E.; Belin, S.; Therizols, G.; Morel, A.P.; Solano-Gonzalez, E.; Vendrell, J.A.; Hacot, S.; Mertani, H.C.; Albaret, M.A.; et al. P53 acts as a safeguard of translational control by regulating fibrillarin and rRNA methylation in cancer. Cancer Cell 2013, 24, 318-330. [CrossRef]

68. Yoon, A.; Peng, G.; Brandenburger, Y.; Zollo, O.; Xu, W.; Rego, E.; Ruggero, D. Impaired control of IRES-mediated translation in x-linked dyskeratosis congenita. Science 2006, 312, 902-906. [CrossRef]

69. Yu, Y.; Ji, H.; Doudna, J.A.; Leary, J.A. Mass spectrometric analysis of the human 40s ribosomal subunit: Native and HCV IRES-bound complexes. Protein Sci. A Publ. Protein Soc. 2005, 14, 1438-1446. [CrossRef]

70. Bellodi, C.; Kopmar, N.; Ruggero, D. Deregulation of oncogene-induced senescence and p53 translational control in x-linked dyskeratosis congenita. EMBO J. 2010, 29, 1865-1876. [CrossRef]

71. Bellodi, C.; Krasnykh, O.; Haynes, N.; Theodoropoulou, M.; Peng, G.; Montanaro, L.; Ruggero, D. Loss of function of the tumor suppressor DKC1 perturbs p27 translation control and contributes to pituitary tumorigenesis. Cancer Res. 2010, 70, 6026-6035. [CrossRef] [PubMed]

72. Jack, K.; Bellodi, C.; Landry, D.M.; Niederer, R.O.; Meskauskas, A.; Musalgaonkar, S.; Kopmar, N.; Krasnykh, O.; Dean, A.M.; Thompson, S.R.; et al. rRNA pseudouridylation defects affect ribosomal ligand binding and translational fidelity from yeast to human cells. Mol. Cell 2011, 44, 660-666. [CrossRef]

73. Rocchi, L.; Pacilli, A.; Sethi, R.; Penzo, M.; Schneider, R.J.; Trere, D.; Brigotti, M.; Montanaro, L. Dyskerin depletion increases Vegf mRNA internal ribosome entry site-mediated translation. Nucleic Acids Res. 2013, 41, 8308-8318. [CrossRef] [PubMed]

74. Beyer, S.; Kristensen, M.M.; Jensen, K.S.; Johansen, J.V.; Staller, P. The histone demethylases Jmjd1a and Jmjd2b are transcriptional targets of hypoxia-inducible factor HIF. J. Biol. Chem. 2008, 283, 36542-36552. [CrossRef] [PubMed]

75. Faye, M.D.; Holcik, M. The role of IRES trans-acting factors in carcinogenesis. Biochim. Biophys. Acta 2015, 1849, 887-897. [CrossRef]

76. Vaysse, C.; Philippe, C.; Martineau, Y.; Quelen, C.; Hieblot, C.; Renaud, C.; Nicaise, Y.; Desquesnes, A.; Pannese, M.; Filleron, T.; et al. Key contribution of eIF4H-mediated translational control in tumor promotion. Oncotarget 2015, 6, 39924-39940. [CrossRef]

(C) 2019 by the authors. Licensee MDPI, Basel, Switzerland. This article is an open access article distributed under the terms and conditions of the Creative Commons Attribution (CC BY) license (http://creativecommons.org/licenses/by/4.0/). 